\title{
Integrated analysis of IncRNA and mRNA in liver of Megalobrama amblycephala post Aeromonas hydrophila infection
}

\author{
Qianhui Sun ${ }^{1,2}$, Jixiu Wang ${ }^{1,2}$, Guowen Wang ${ }^{1,2}$, Huanling Wang ${ }^{1,2}$ and Hong Liu ${ }^{1,2^{*}}$
}

\begin{abstract}
Background: As non-coding RNA molecules of more than 200 bp in length, long non-coding RNAs (IncRNAs) play a variety of roles in biological processes, including regulating the immune responses to bacterial infections. In recent years, there have been many in-depth studies on mammalian IncRNAs, but the relevant studies in fish are very limited. Meanwhile, since IncRNAs are not conserved among species, it is difficult to apply the existing results directly to unstudied species.

Results: To obtain the information of IncRNAs in Megalobrama amblycephala, one of the most economically important freshwater fish in China, also to better understand the biological significance of IncRNAs in the immunity system, the fish liver at 0, 4, 12, 24, and $72 \mathrm{~h}$ post Aeromonas hydrophila infection (hpi) were obtained for IncRNAsequencing (IncRNA-seq). A total of 14,849 IncRNAs were identified, and 2196 IncRNAs showed significant differences at different time points post A. hydrophila infection. Gene Ontology (GO) annotation and Kyoto Encyclopedia of Genes and Genomes (KEGG) pathway analyses showed that the target genes of the differentially expressed IncRNAs were enriched in several pathways related to immune such as apoptosis, inflammation, and immune response. Time-specific modules were then identified, using weighted correlation network analysis (WGCN A), and 28 modules significantly correlated with different time point after infection were found. Furthermore, four immune-related genes and six IncRNAs in the time-specific modules were subsequently verified by RT-qPCR.

Conclusions: The above findings reveal the discovery of widespread differentially expressed IncRNAs in the $M$. amblycephala liver post A. hydrophila infection, suggesting that IncRNAs might participate in the regulation of host response to bacterial infection, enriching the information of IncRNAs in teleost and providing a resources basis for further studies on the immune function of IncRNAs.
\end{abstract}

Keywords: LncRNAs, Immune response, Bacterial infection, M. amblycephala, Teleost, ceRNA

\footnotetext{
* Correspondence: liuhong59@mail.hzau.edu.cn

${ }^{1}$ College of Fisheries, Key Lab of Freshwater Animal Breeding, Ministry of Agriculture and Rural Affair / Key Lab of Agricultural Animal Genetics, Breeding and Reproduction of Ministry of Education, Huazhong Agricultural University, Wuhan 430070, China

${ }^{2}$ Engineering Research Center of Green Development for Conventional Aquatic Biological Industry in the Yangtze River Economic Belt, Ministry of Education, Wuhan 430070, China
}

(c) The Author(s). 2021 Open Access This article is licensed under a Creative Commons Attribution 4.0 International License, which permits use, sharing, adaptation, distribution and reproduction in any medium or format, as long as you give appropriate credit to the original author(s) and the source, provide a link to the Creative Commons licence, and indicate if changes were made. The images or other third party material in this article are included in the article's Creative Commons licence, unless indicated otherwise in a credit line to the material. If material is not included in the article's Creative Commons licence and your intended use is not permitted by statutory regulation or exceeds the permitted use, you will need to obtain permission directly from the copyright holder. To view a copy of this licence, visit http://creativecommons.org/licenses/by/4.0/. The Creative Commons Public Domain Dedication waiver (http://creativecommons.org/publicdomain/zero/1.0/) applies to the data made available in this article, unless otherwise stated in a credit line to the data. 


\section{Background}

Long noncoding RNAs (lncRNAs) are operationally defined as non-coding RNA molecules with a length of more than 200 base-pairs (bp) [1]. LncRNAs include intergenic lncRNAs (lincRNAs), antisense lncRNAs, intronic lncRNAs, and sense lncRNAs [2]. As multifunctional molecules, lncRNAs play important roles in multiple biological processes by interacting with RNA, DNA, or proteins to change the expression of proteincoding genes [3], which can regulate diverse cellular processes, including disease process, development and cell proliferation [4].

Since the expression pattern of IncRNAs is closely related to the development of many diseases $[5,6]$, lncRNAs have gradually become a research hotspot in the field of life sciences. LncRNAs regulate gene expression at the epigenetic, transcriptional and posttranscriptional levels [7] and previous studies have shown that they play an important regulatory role in the innate immune system $[8,9]$. The adaptive immune cells provide vital immune protection under the guidance of lncRNAs [3]. Meanwhile, microRNAs (miRNAs) can regulate gene expression post-transcriptionally [10]. Bacterial infection in mammals can interferes with miRNA expression, thus altering the mechanism of immune signal transduction, autophagy, or apoptosis [11]. As competing endogenous RNA (ceRNA), messenger RNAs, transcribed pseudogenes, and lncRNAs form a largescale regulatory network across the transcriptome to communicate with each other through miRNA response elements (MREs) [12]. The MREs in coding and noncoding transcripts affect the expression levels and activities of different ceRNAs [13], which were associated with a variety of diseases [14]. As miRNA sponges, lncRNAs play a role in immunity by competitively inhibit the ability of miRNAs to interact with their mRNA targets $[15,16]$.

Most studies about immune-related lncRNAs are mainly focused on mammalian species, especially human and mouse. Previous research has established that IncRNAs play a paramount role in immunity by inducing immune gene expression, regulating cytokine genes, adaptive immune cells, and participating in RNAprotein, RNA-DNA, or RNA-RNA interactions [3]. The IncRNA transcripts significantly enrich in autoimmune and immune-related disorders (AID) loci [17], which makes lncRNAs a biomarker for human disease or a target for medical detection. For example, lncRNAs are involved in the host response to viral infection and innate immunity during SARS-CoV infection in mouse [18]. Li et al. (2018) find that lncRNA MEG3-4 is more competitive than miR-138 when combining with proinflammatory cytokine interleukin-1 $\beta(I L-1 \beta)$, thus intensifying the inflammatory responses to bacterial infection in mice
[19]. Additionally, it's shown that lncRNAs are specifically involved in the mammalian cell response toward bacterial infections [11].

Due to the low evolutionary conservation of lncRNAs across species [20], the research result of lncRNAs in mammalian species can hardly be applied to aquaculture species. Up to now, a few studies have attempted to explain the role of IncRNA in teleost. When exposed to $\beta$ diketone antibiotics (DKAs), the lncRNAs in zebrafish (Danio rerio) are abnormally expressed and their potential target genes might play roles in immunity [21]. Besides, antisense lncRNA PU.1 is found to be involved in the adaptive immunity of zebrafish [22]. After infected with Flavobacterium psychrophilum, lncRNAs mediate anti-bacterial immune response in rainbow trout (Oncorhynchus mykiss) [23]. RNA sequencing of Atlantic salmon (Salmo salar) infected with Piscirickettsia salmonis suggests that lncRNAs are associated with the genes of endocytosis and iron homeostasis, such as clathrin, hepcidin, and haptoglobin [24].

Aeromonas hydrophila, the main pathogen that causes bacterial septicemia in freshwater fish, can lead to high mortality and bring about serious economic losses to the freshwater aquaculture industry. Megalobrama amblycephala is an important economic freshwater fish in China, meanwhile it is sensitive to A. hydrophila and can be seriously harmed by bacterial septicemia. The liver has the functions of secreting bile, detoxifying, and storing glycogen, and is one of the most core organs for the body to maintain physiological functions. At the same time, the liver has been generally accepted as a major immune organ in teleost [25-27]. As in mammals, hepatocytes are the prime source of acute phase response in fish, and that pro-inflammatory cytokines induce transcription of their genes [28]. Given that lncRNA is an essential part of the immunological process and related knowledge in fish is quite limited, herein, we conducted a comprehensive lncRNAs sequencing in the liver of $M$. amblycephala post A. hydrophila infection and performed functional annotation analysis based on the Gene Ontology (GO) and Kyoto Encyclopedia of Genes and Genomes (KEGG) databases. We identified the co-localization of lncRNAs and genes at different time points post infection by using WGCNA (weighted correlation network analysis). This research will enrich the IncRNA database of teleost and contribute to a better understanding of the role of lncRNAs in the immune response of teleost.

\section{Results}

Identification and characterization of mRNA and IncRNA in the M. amblycephala liver

To identify lncRNAs expressed in the M. amblycephala liver at different time points after $A$. hydrophila 
infection, 15 cDNA libraries (5 time points, 3 repetitions per time point) were constructed and sequenced. Clean reads totaling $163.21 \mathrm{~Gb}$ were obtained. The mean GC content of the 15 libraries was $48.23 \%$ and the Q30 of each sample was no less than $95.68 \%$, suggesting that the sequencing data was highly reliable. On average, $67,576,141$ mapped reads were obtained from the clean data (Additional files 1 and 2: Table S1 and S2). A total of 9011 differentially expressed genes (DEGs) were identified. The intersection of the CPC, CNCI, Pfam, and CPAT finally yielded 14,849 IncRNA transcripts, which were classified as 10,272 lincRNAs, 2691 intronic lncRNAs, 1161 sense lncRNAs, and 725 anti-sense IncRNAs (Fig. 1).

To study the basic features of lncRNAs in the $M$. amblycephala liver, lncRNAs were identified and aligned with mRNAs. The results showed that there were 12,689 lncRNAs corresponding to 887,446 target genes (Additional file 3: Table S3). Furthermore, several lncRNAs acting in trans were found to target protein-coding genes specifically related to innate immunity, including interleukin 6 ( IL 6), hepcidin, transferrin, and complement C3. Some mRNAs (complement C3) are regulated by multiple lncRNAs (e.g. MSTRG.9317.1 and MSTR G.104056.1), and a single lncRNA (MSTRG.97410.1) can target multiple mRNAs (IL 6, NF-kB2, TRAF2, and hepcidin), indicating the functional intersection of these lncRNAs and their common potential target genes.

Compared to $0 \mathrm{~h}$, there were 1133 differentially expressed lncRNAs (DE lncRNAs) at $4 \mathrm{hpi}, 1164 \mathrm{DE}$ lncRNAs at $12 \mathrm{hpi}, 482 \mathrm{DE}$ lncRNAs at $24 \mathrm{hpi}$, and 506
DE lncRNAs at $72 \mathrm{hpi}$, respectively (FDR $<0.05$ and $\mid \log 2$ (Fold Change) $\mid \geq 1$ ) (Fig. 2). To further analyze the interactions among different time points, we constructed a Venn diagram using the DEGs and DE lncRNAs that were differentially expressed in comparisons of 4 hpi vs 0 hpi, 12 hpi vs 0 hpi, 24 hpi vs 0 hpi, and 72 hpi vs 0 hpi, respectively. A total of 557 overlapping sequences from 9011 DEGs and 59 overlapping sequences from 2196 DE lncRNAs were identified among all the 4 comparisons (Fig. 3). Heat maps indicated overt different clusters before and after A. hydrophila infection (Fig. 4). Notably, the results showed a relatively large difference in mRNAs and lncRNAs expression trends among different time points although the time difference was only a few hours.

\section{GO and KEGG enrichment analyses of target genes of DE IncRNAs}

Based on the GO database, the target genes of $\mathrm{DE}$ lncRNAs were assigned to the biological processes, cellular components, and molecular function, respectively. The significantly enriched GO terms for DEGs and target genes of DE lncRNAs in each comparison between different time points were shown in Additional files 4 and 5 (Table S4 and S5). In the four comparisons, the significant GO terms of the DEGs were mainly associated with "I-kappaB kinase/NF-kappaB signaling", "hydrolase activity", "oxidation-reduction process", "ncRNA processing", "nuclear ncRNA surveillance", "response to metal ion", "cofactor binding", "lipid biosynthetic process", and so on (Additional file 4: Table S4).

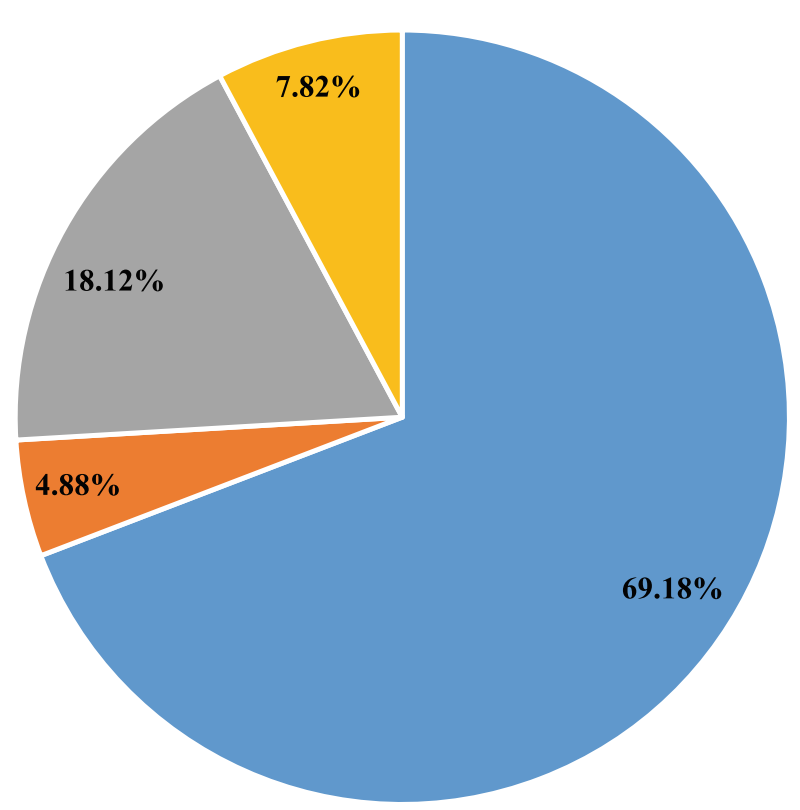

- LincRNA

- Antisense-IncRNA

- Intronic-IncRNA

- Sense-IncRNA

Fig. 1 Percentage of different types of predicted IncRNAs in the Megalobrama amblycephala liver post Aeromonas hydrophila infection 
A
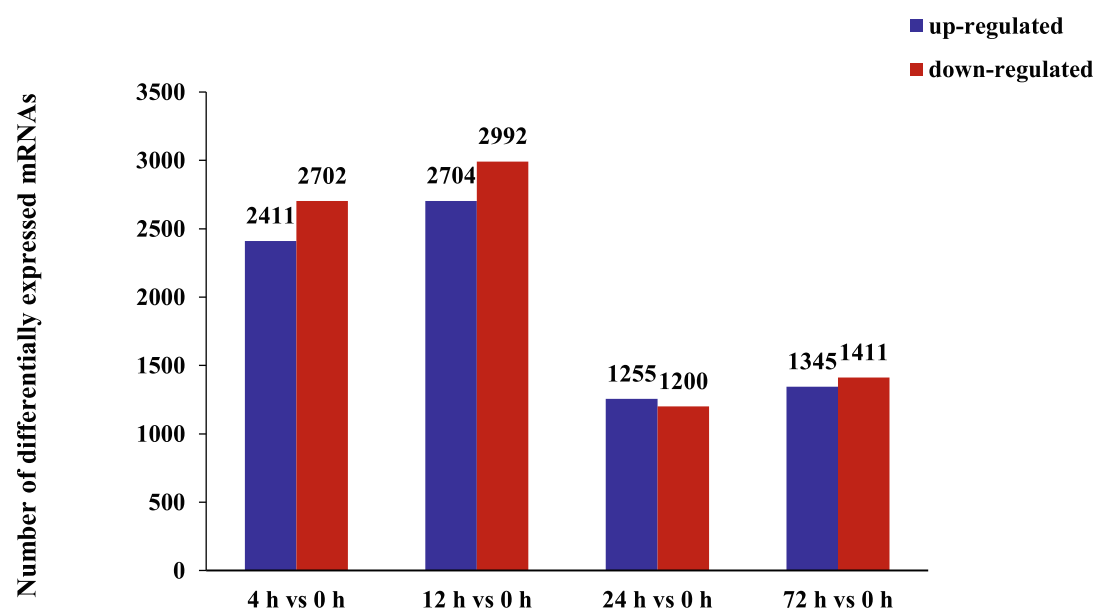

B

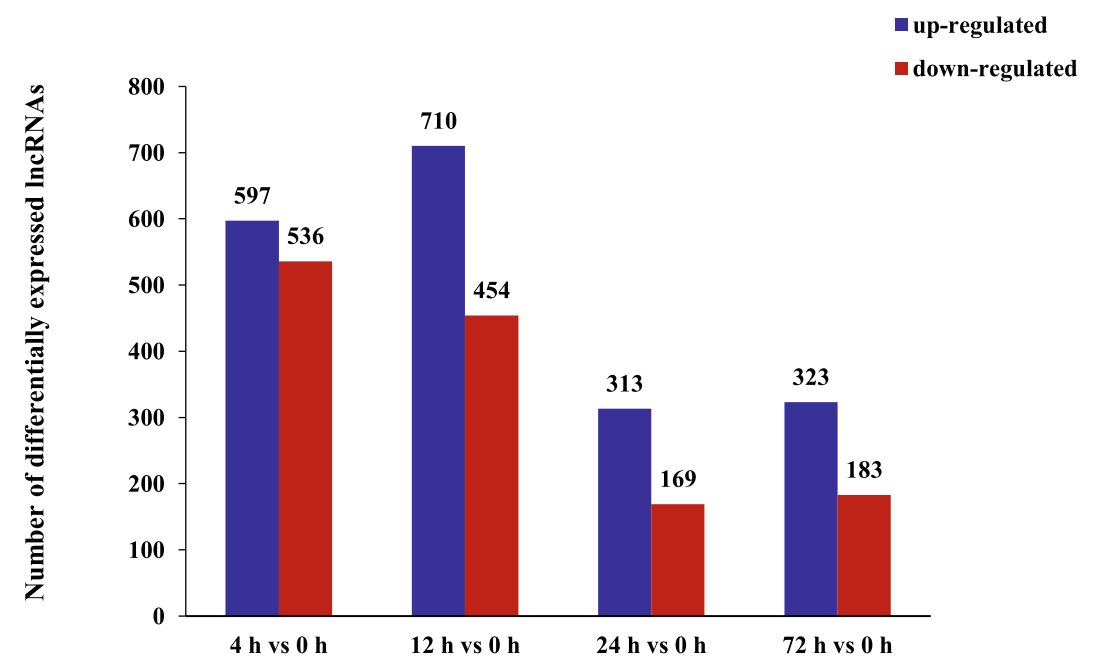

Fig. $\mathbf{2}$ Number of differentially expressed mRNAs (A) and IncRNAs (B) in the Megalobrama amblycephala liver post Aeromonas hydrophila infection. The blue and red columns represent significantly up- and down-regulated, respectively, and the number at the top of the column indicates the number of differentially expressed mRNAs or IncRNAs

In contrast, no significant pathway of the target genes of DE lncRNAs was identified at 24 and 72 hpi. The significant GO terms of the target genes were mainly associated with "catalytic activity", "endoplasmic reticulum cytoplasm", and "golgi apparatus" at 4 and 12 hpi (Additional file 5: Table S5).

KEGG were performed to understand the enrichment of the lncRNA target genes and to reveal the functions of the DE lncRNAs. KEGG analysis demonstrated that most of the significantly enriched pathways of the target genes of DE lncRNAs post infection belong to the pathways including "adipocytokine signaling pathway", "herpes simplex infection", "NOD-like receptor signaling pathway", "PPAR signaling pathway", "protein export", "protein processing in endoplasmic reticulum", "RIG-Ilike receptor signaling pathway", "TGF-beta signaling pathway", and "Toll-like receptor signaling pathway" (Additional file 6: Table S6).

Weighted correlation network analysis (WGCNA) and RTqPCR validation

We combined all the expression matrix of both proteincoding genes and lncRNAs as the input file for WGCNA to identify modules. After excluding deletion and outlier values, an expression matrix of 13,460 transcripts (including 916 lncRNAs and 12,544 protein-coding genes) were obtained for further analysis. We explored and identified the correlations among modules according to 


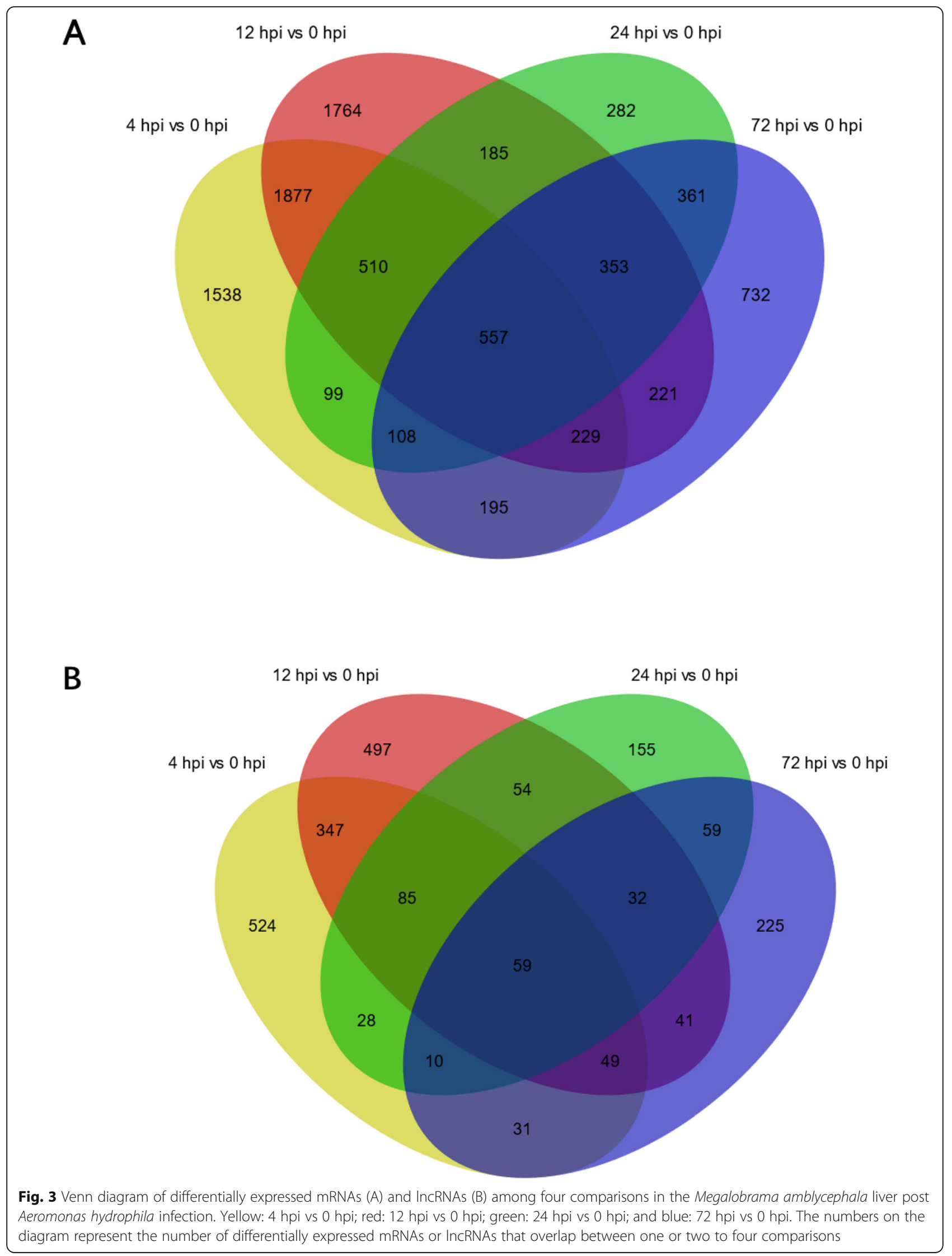




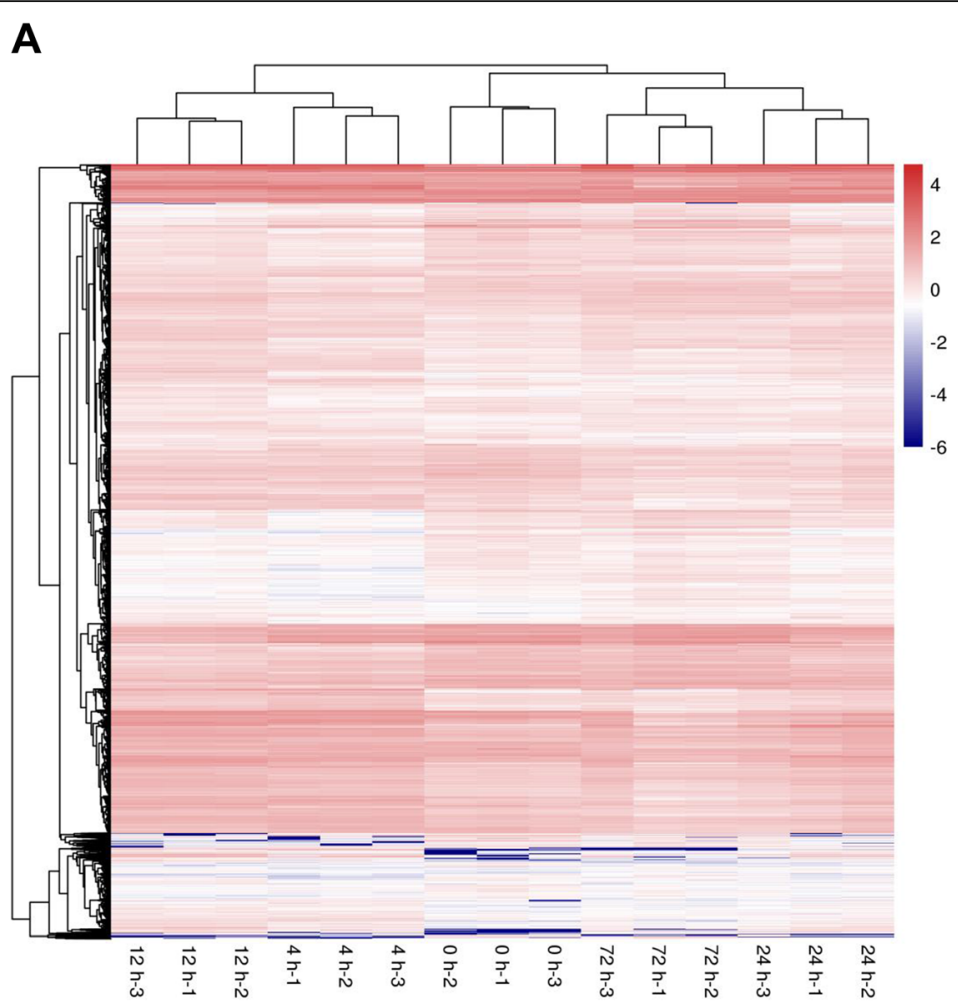

B

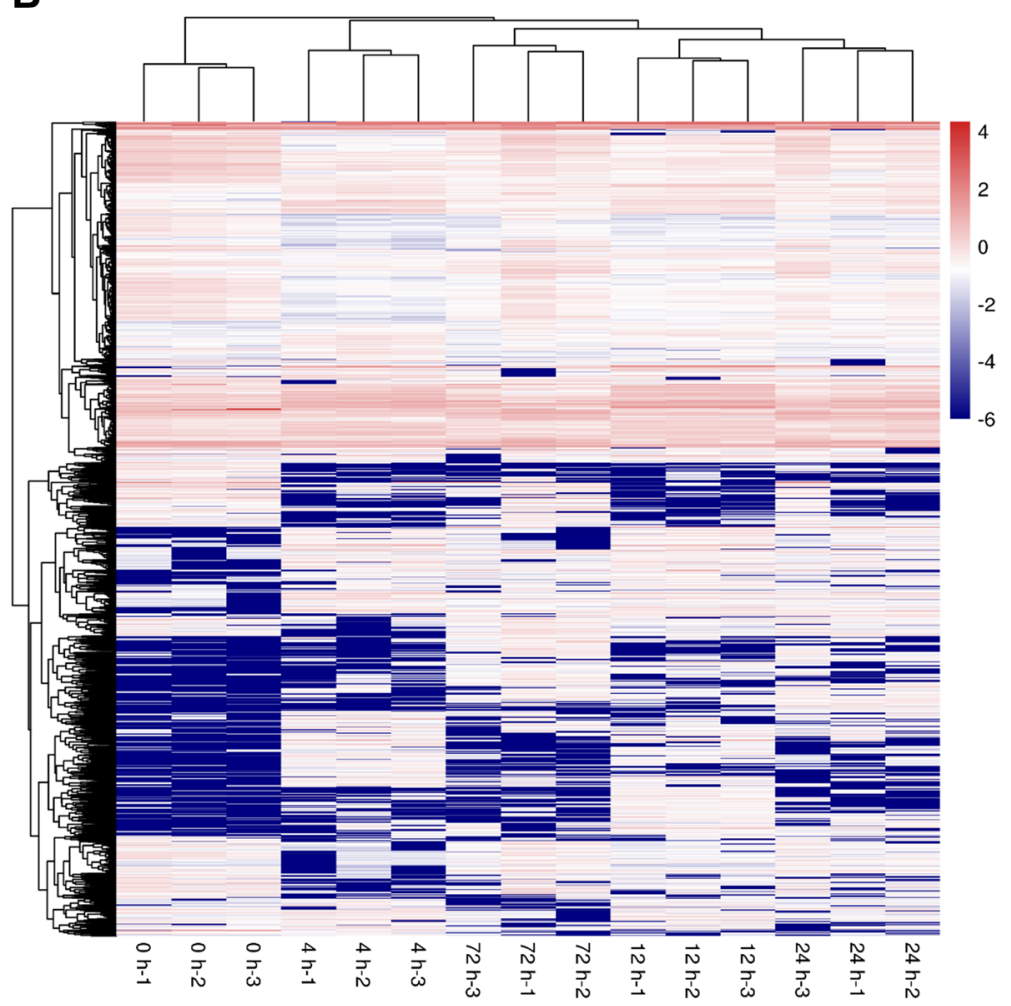

Fig. 4 Expression profile of DEGs and DE IncRNAs in the Megalobrama amblycephala liver post Aeromonas hydrophila infection based on RNA-seq (A) Heatmap of expression profile for the DEGs that showed significant expression changes. (B) Heatmap of expression profile for the DE IncRNAs that showed significant expression changes. Red: relatively high expression level; Blue: relatively low expression level. The darker the red color, the higher the expression level, and the darker the blue color, the lower the expression level 
A Cluster Dendrogram

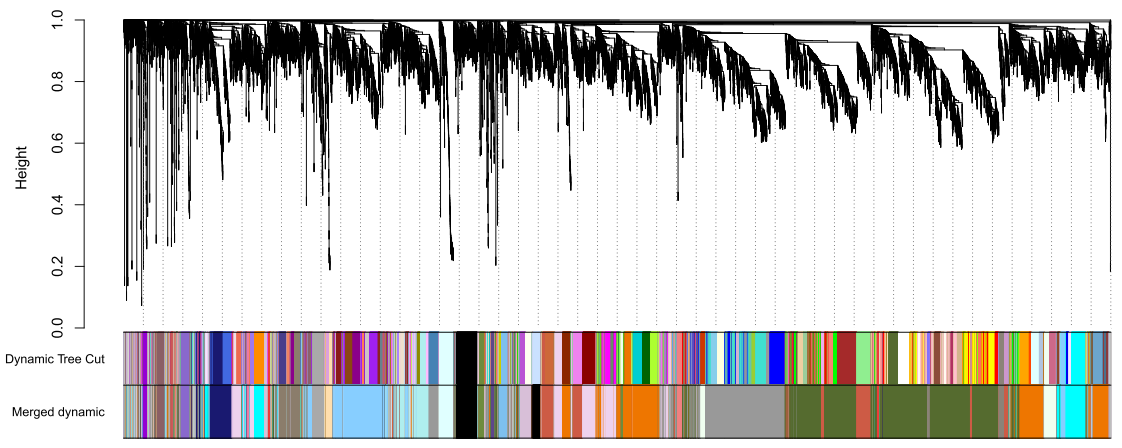

B Module-trait relationships

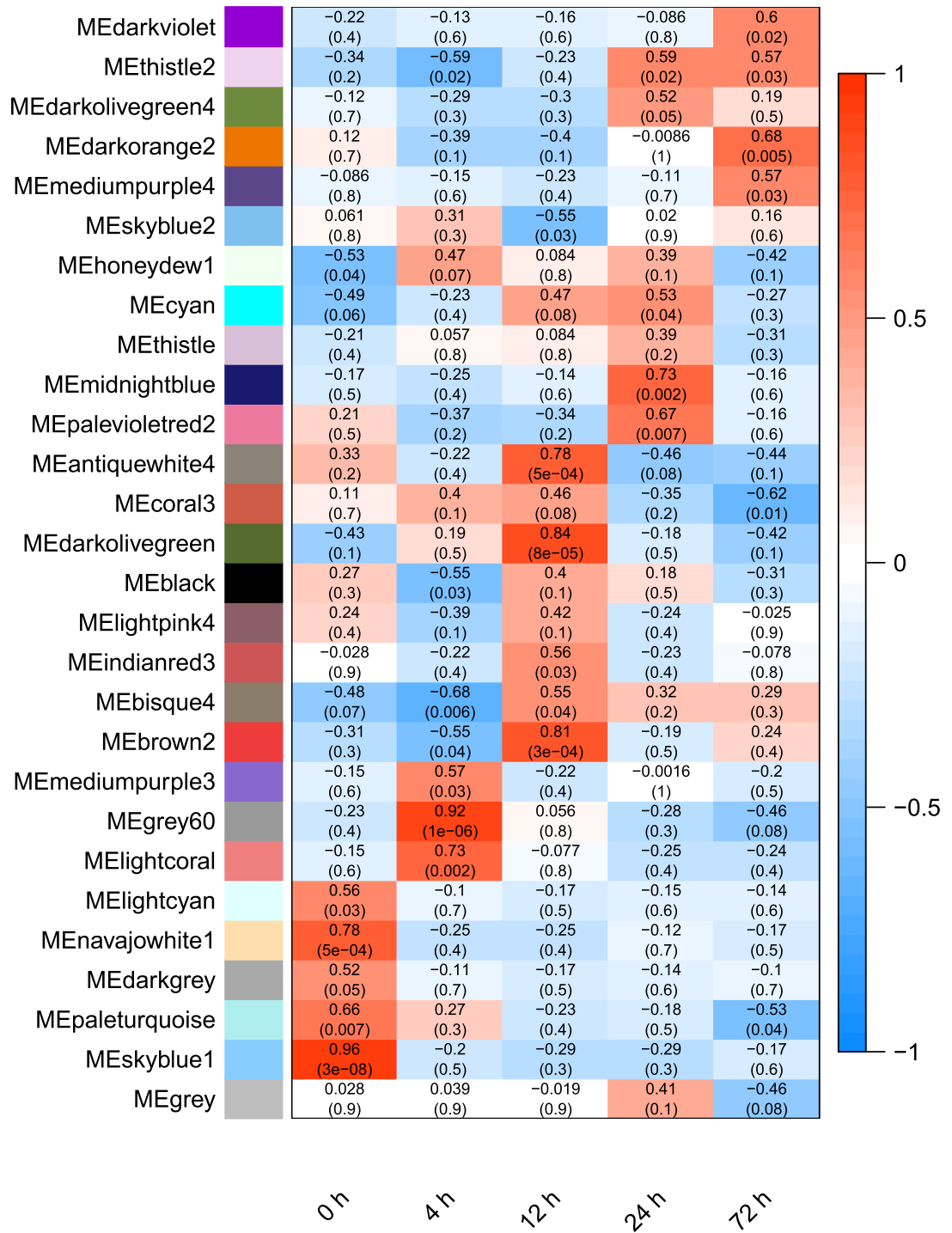

Fig. 5 (See legend on next page.) 
(See figure on previous page.)

Fig. 5 Weighted gene co-expression network analysis (WGCNA) of mRNAs and IncRNAs in the Megalobrama amblycephala liver post Aeromonas hydrophila infection. (A) The dendrogram of all genes is clustered based on a dissimilarity measure (1-TOM). Each single leaf in the tree represents a single gene, the major tree branches constitute 28 distinct modules and are shown in different colors. (B) Heatmap of the module-trait relationships. Each row corresponds to a module, and each column represents the specific time points after infection with Aeromonas hydrophila. The right color panel represents Pearson's $r$ correlation coefficient. Red for positive correlation and blue for negative correlation. Each cell contains the corresponding correlation and $p$-value

clustering analysis. The resulting gene dendrograms and respective module with different colors were shown in Fig. 5A and 28 modules were found to be significantly correlated with different time point post infection (Fig. $5 B)$.

Six modules $(P<0.05)$, which were significantly positively correlated with different time points post infection were selected for co-expression analysis (Fig. 6). Grey 60 $(r=0.92, P=1 \mathrm{e}-06)$ and mediumpurple $3(r=0.57, P=$ $0.03)$ modules, which included many immune related genes such as $H A C E 1, I L-1 \beta, N F-k B$, transferrin, $p 53$, hepcidin and so on were correlated with $4 \mathrm{hpi}$. The genes such as Derl1, Hsp90, and calreticulin-like in the darkolivegreen $(r=0.84, P=8 \mathrm{e}-05)$ module, which might play important roles at $12 \mathrm{hpi}$, were enriched in the "protein processing in the endoplasmic reticulum" pathway. The midnightblue module $(r=0.73, P=0.002)$ included genes such as egl-9 family hypoxia-inducible factor $1 \alpha$ were correlated with $24 \mathrm{hpi}$, whereas the darkviolet $(r=0.6, P=0.02)$ and darkorange $2(r=0.68, P=$ $0.005)$ modules which included perforin, NLRC3-like, and $D M B T 1$-like genes, might play important roles at 72 hpi.

RT-qPCR was used to verify expression of the selected six DE lncRNAs and four DE genes. The results showed that the expression trends of lncRNAs and target genes identified by high-throughput sequencing were consistent with those identified by RT-qPCR (Fig. 7). The expression of MSTRG.55000.1 and MSTRG.81802.1 was up-regulated at 4 hpi and gradually down-regulated after 12 hpi. The hepcidin gene trans-regulated by those lncRNAs has a similar expression trend. This indicates that lncRNAs have complex functions.

\section{Discussion}

Although there have been many in-depth studies in mammals, the study of fish lncRNA is very inadequate and the results of the former cannot be applied to the latter due to the non-conservativeness of lncRNAs. Several studies indicate that IncRNAs are involved in the immune regulation of teleost fish. For example, of the 5636 non-overlapping lncRNA loci identified, 3325 are differentially expressed during ISA virus (ISAV) infection in the liver of Atlantic salmon [29]. A total of 11,462 lncRNAs are expressed in the liver of Atlantic salmon infected with Piscirickettsia salmonis, of which
993 lncRNAs are differentially expressed [30]. There are 8463 lncRNAs identified in the spleen of Larimichthys crocea infected with vibrio parahaemolyticus [31]. Consistently, in this study, IncRNA-seq was performed on the $M$. amblycephala liver at $0,4,12,24$, and 72 hpi post A. hydrophila infection. A total of 14,849 lncRNAs were identified, of which 2196 lncRNAs were differentially expressed. The dynamic changes of mRNAs are closely related to the physiological status of fish. Like mRNAs, lncRNAs may have spatial and temporal expression with potentially important roles during bacterial infection. Meanwhile, the expression of lncRNAs in the M. amblycephala liver showed significant difference among different time points post challenge. After challenge with $A$. hydrophila, the mortality rate and pathological damage of $M$. amblycephala peaked at $48 \mathrm{hpi}$ and then gradually recovered [32]. We assume that in the early stages post challenge, bacteria proliferated rapidly, and the innate immune of the body quickly responded to kill bacteria. In the late stages post challenge, the immune system continued to kill bacteria in the survived fish, and the bacteria were completely defeated finally. Overall, with dynamic changes of competition between the proliferation of bacteria and the killing bacteria of the immune system, lncRNAs also presented a very dynamic change in the short-term post challenge. The RT-qPCR results further validated that the expression of the DE IncRNAs was consistent with the sequencing data.

There are different kinds of lncRNAs such as lincRNA, intronic lncRNA, sense lncRNA, and antisense lncRNA. It has been reported that most lincRNAs are more likely to act in cis through transcriptional interference [2]. Cisnatural antisense lncRNAs may regulate gene expression at the transcription level. The large number of intronic IncRNAs may be pre-mRNA fragments [33], which are transcribed and may encode exons within rarelyexpressed transcripts [2]. Among the obtained lncRNAs in $M$. amblycephala, $69.2 \%$ were lincRNA, $18.1 \%$ were intronic lncRNA, $7.8 \%$ were sense lncRNA, and $4.9 \%$ were antisense lncRNA. Multiple types of lncRNAs coexisted in this study, and lincRNAs accounted for the largest proportion, indicating that lncRNAs may play multiple biological functions through multiple pathways, and the role of lincRNAs may be the most important.

The DEGs and target genes of DE lncRNAs at different time points were analyzed separately here. GO 


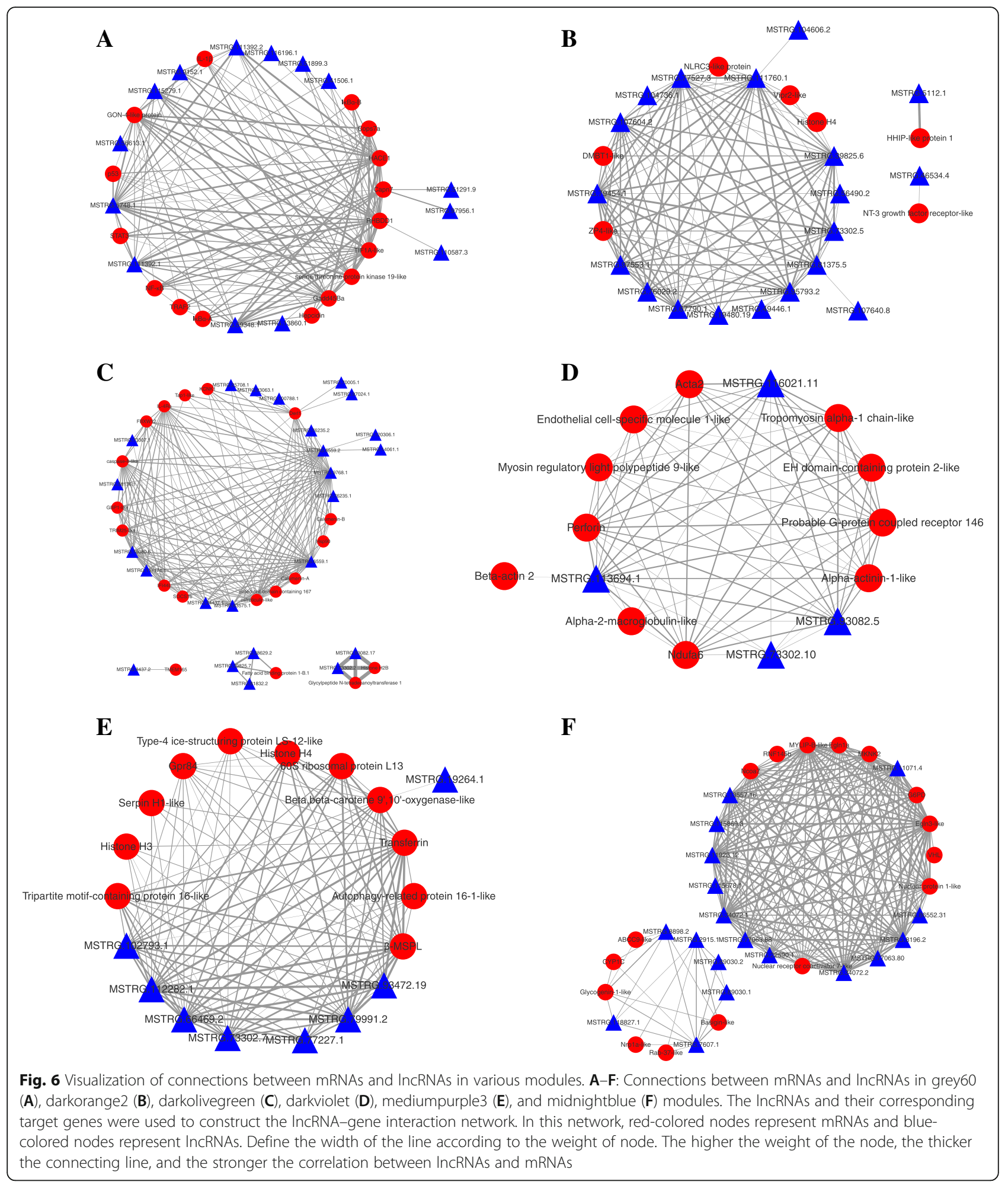

analysis showed that both DEGs and target genes of DE lncRNAs were mostly enriched in oxidoreductase activity and immune-related pathways, such as inflammatory response, and hydrolase activity post infection, whose function in the immune system have been reported in previous studies [34-38]. Oxidoreductases are enzymes that catalyze many redox reactions in normal cells [39]. Gostner et al. (2013) [34] indicated that redox reactions could initiate cytocidal reaction within the pathogen defense and trigger immune response, which are further 
involved in the process of cellular restorative. Xanthine oxidoreductase (XOR) has the capacity to produce both ROS and NO [35]. It is reported that the A. hydrophila infection affect ROS and NO reactive free radicals and induce an inflammatory response in zebrafish [36]. The iNOS is related to the immune response, which can induce NO to participate in immune regulation and antitumor mechanism [37]. Furthermore, the inducible isoform of nitric oxide synthase (iNOS) can be induced by cytokines such as interleukin, tumor necrosis factor, and interferon in the process of many diseases [37]. Triggering lyososomal rupture in dendritic cells might be to elevate intracellular ROS production for promoting antigen cross presentation [38].

In this study, KEGG pathway analysis showed that the target genes of the DE lncRNAs at different time points were mostly significantly enriched in the innate immune response pathways such as "adipocytokine signaling pathway", "RIG-I-like receptor signaling pathway", "herpes simplex infection", and "Toll-like receptor signaling pathway", which further confirmed that lncRNAs might participate in the regulation of fish immunity. Adipocytokine signaling pathway was one of the frequent pathways present in different time points comparisons in our study. It has been reported that the increase of genes expression related to various lipid and energy metabolism could reduce the inflammation in the body [40]. The peroxisome proliferator-activated receptors (PPARs) can modulate the expression of genes involved in lipid metabolism, maintenance of metabolic homeostasis, and inflammation [41]. After Toll-like receptors (TLR) or cytokine receptors in innate immune cells activate the intracellular signaling pathways to participate in immune responses, the expression of lncRNA in specific celltypes is induced [3]. This strongly indicates that these pathways play essential roles in the M. amblycephala response to A. hydrophila infection.

Obviously, we need more in-depth molecular mechanisms research to elucidate the specific function of lncRNAs to their target genes. The target genes of lncRNA in the module could indicate their biological processes and functions. Thus, we integrated lncRNAs and their target genes using WGCNA and BMKCloud (www.biocloud.net), and several highly correlated lncRNAs and mRNAs in six time-specific modules were identified. This genetic network may aid in functional analysis of lncRNAs, as most of them have not yet been identified as functional. These modules of co-expressed genes revealed the complex defense network, indicating diverse regulatory mechanisms of $M$. amblycephala post bacterial infection. For example, hepcidin was highly connected with $4 \mathrm{hpi}(\mathrm{COR}=0.98)$ in the grey $60 \mathrm{mod}$ ule in the present study. We found that DEGs were significantly enriched in "iron ion binding" at 4 and $12 \mathrm{hpi}$.
Previous studies have shown that there is a close connection between iron and innate immunity [42], and iron metabolism-related genes such as ferritin and transferrin have been verified to be related to immunity [43, 44]. Hepcidin is the main regulator of iron homeostasis and also the mediator of innate immunity [45]. The coexpressed lncRNAs related to hepcidin and other immune related genes in the iron metabolism pathway were analyzed by using BMKCloud and the co-expressed lncRNAs of those genes were selected for expression verification by RT-qPCR. The hepcidin and other immune related genes were up-regulated post bacterial infection, indicating that these genes played antibacterial immunity role after bacterial infection.

\section{Conclusions}

This study explored the response of lncRNAs in the $M$. amblycephala liver to A. hydrophila infection. A total of 14,849 lncRNAs and 2196 DE lncRNAs were identified. GO and KEGG pathway analyses showed that the target genes of the DE lncRNAs were enriched in several pathways related to immune such as apoptosis, inflammation, and immune response. In addition, 28 time-specific modules were found by using WGCNA. Although the complexity of the natural environment cannot be fully explained, this research will enrich the lncRNAs database and contribute to a better understanding of the roles of lncRNAs in the immune response of teleost. Besides, since the lncRNAs can be a biomarker for human disease or a target for medical detection, we hope that our research on lncRNA could contribute to the research and detection of fish diseases. Further experimental studies are still needed on how lncRNAs work in the liver of M. amblycephala, and how it regulates the coexpressed genes involved.

\section{Materials and methods Samples collection}

All the experimental procedures involved fish were approved by the Institutional Animal Care and Use Committee of Huazhong Agricultural University (Wuhan, China). The challenge experiment was conducted according to a previous study [44] with modification. In brief, unvaccinated healthy juvenile $M$. amblycephala $(50 \pm 10 \mathrm{~g})$ were obtained from a fishery farm from Honghu city, Hubei province. The fish were kept in a recirculating freshwater system (temperature: $25-26^{\circ} \mathrm{C}$ ) and fed with a commercial pellet fish feed for 2 weeks before experimental manipulation. The experimental fish were injected intraperitoneally with $0.1 \mathrm{~mL}$ A. hydrophila $(6 \times$ $10^{6} \mathrm{CFU} / \mathrm{mL}$ ). The liver tissues from 9 fish (3 pools with 3 fish per pool) at $0,4,12,24$, and $72 \mathrm{~h}$ post infection (hpi) were collected, respectively. Three liver samples were pooled as one biological duplicate and a total of 15 

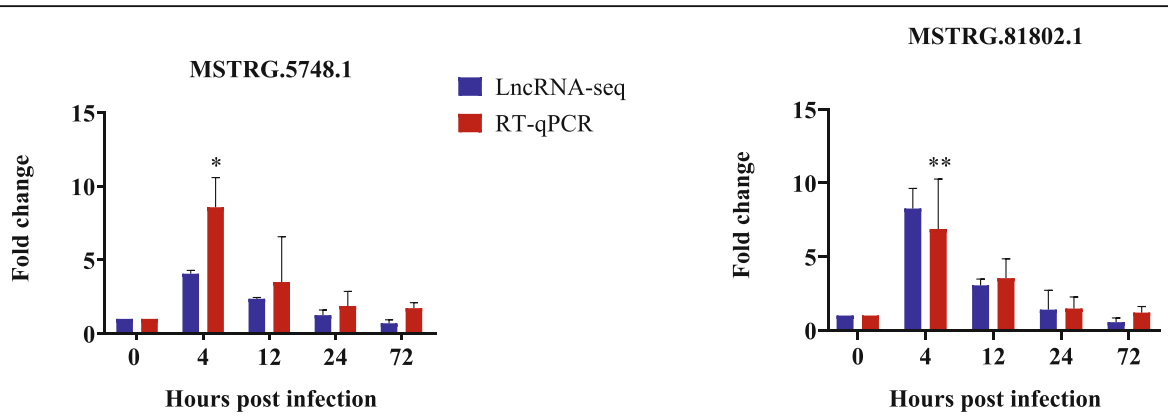

LncRNA-seq

- LncRNA-seg

RT-qPCR

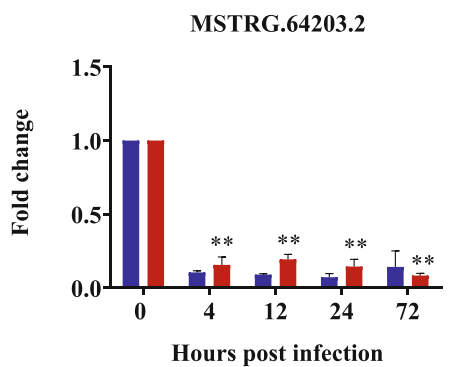

LncRNA-seq

RT-qPCR
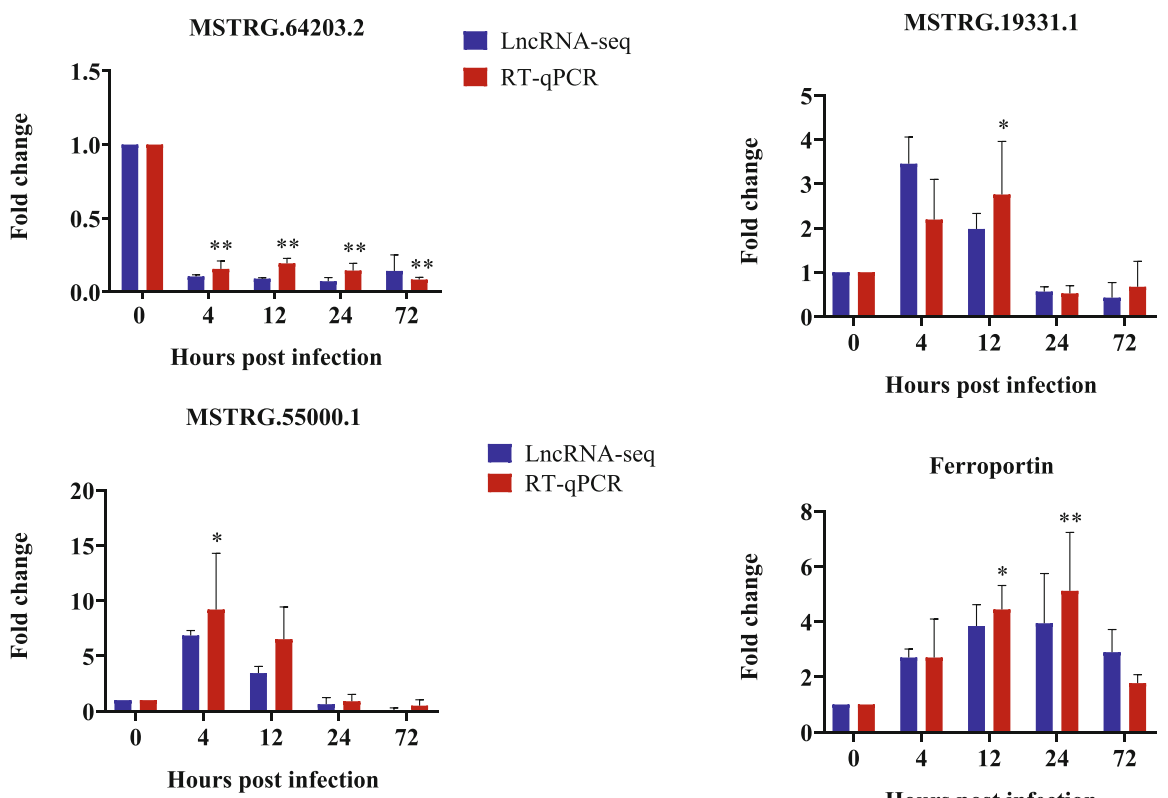

LncRNA-seq RT-qPCR

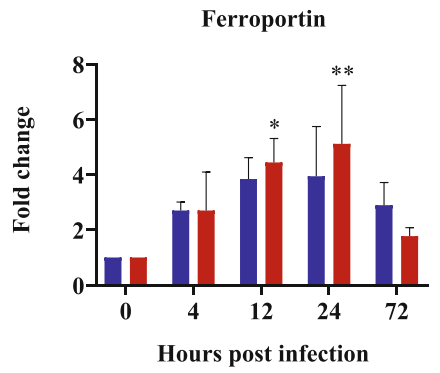

LncRNA-seq

RT-qPCR

MSTRG.78538.13

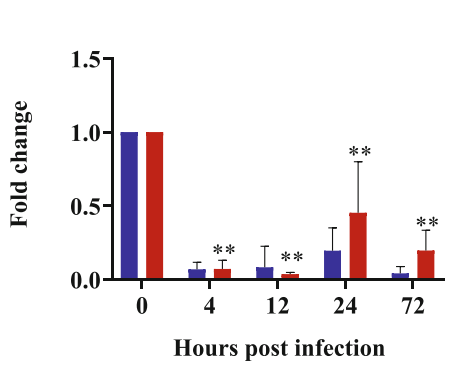

LncRNA-seq

RT-qPCR
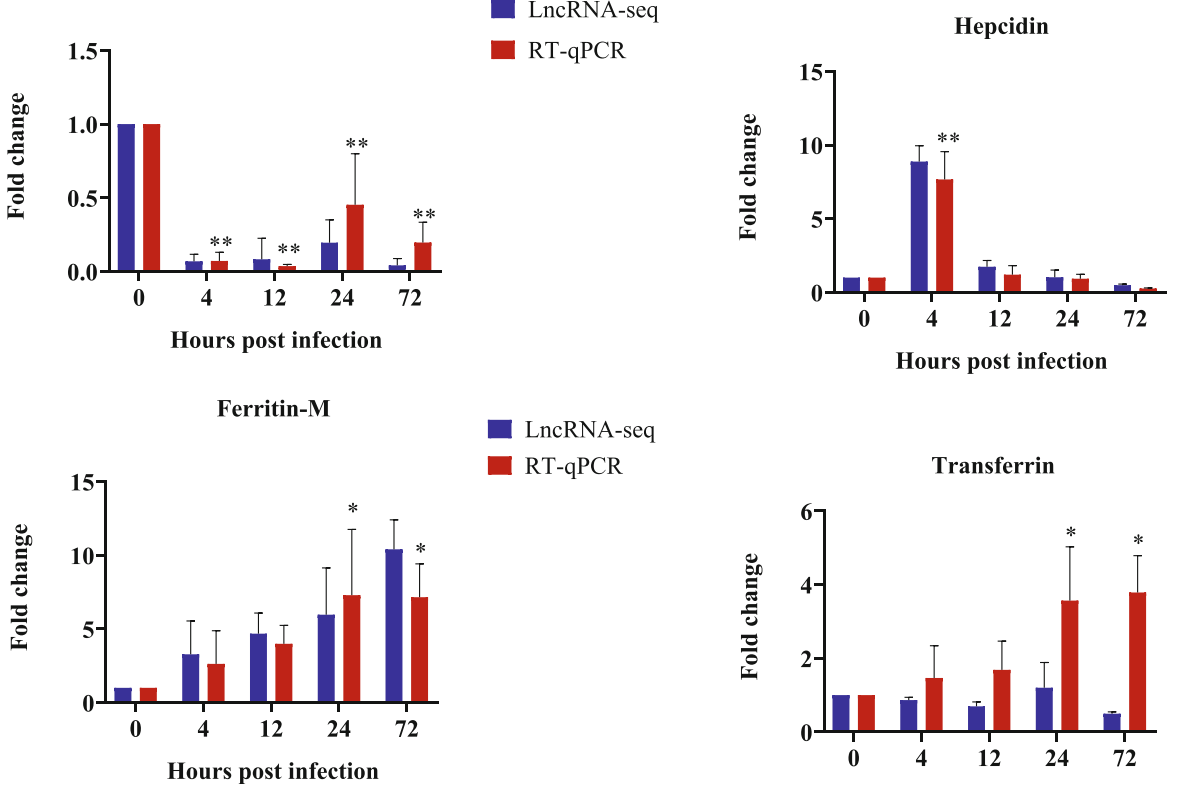

LncRNA-seq

- RT-qPCR

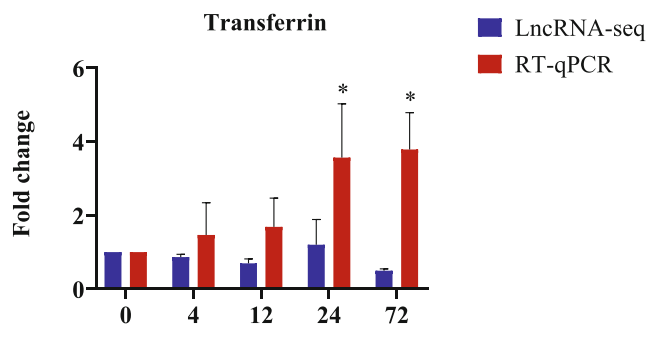

Fig. 7 (See legend on next page.) 
(See figure on previous page.)

Fig. 7 RT-qPCR validation of six differentially expressed IncRNAs and four differentially expressed genes selected. The blue column represents the results of IncRNA-seq, and the red column represents the results of RT-qPCR. Values were described as mean \pm SEM ( $n=3$ pools, with 3 fish per pool). Differences were determined by one-way analysis of variance (ANOVA). The asterisks indicate statistically significant differences $\left({ }^{*}, P<0.05\right.$; **, $P<0.01$ )

samples (3 biological duplicates at 5 time points) were used for later lncRNA-sequencing. The experimental fish were anesthetized with MS 222 at $100 \mathrm{mg} / \mathrm{L}$ before dissection. All samples were flash-frozen in liquid nitrogen and stored at $-80^{\circ} \mathrm{C}$ for further use.

\section{LncRNAs library construction}

After total RNA was extracted using TRIzol reagent (Invitrogen, CA, USA) according to the manufacturer's instructions, its purity, concentration, and integrity were checked to ensure the use of qualified samples for transcriptome sequencing. rRNA was removed by using the Ribo-Zero rRNA Removal Kit (Epicentre, Madison, WI, USA). Sequencing libraries were constructed using the NEBNext $^{\mathrm{R}}$ Ultra $^{\mathrm{Tm}}$ Directional RNA Library Prep Kit for Illumina ${ }^{\mathrm{R}}$ (NEB, USA) following the manufacturer's recommendations. Insert fragments of 150-200 bp in length were purified with AMPure XP Beads (Beckman Coulter, Beverly, USA). Finally, the U chain was degraded, and the cDNA library was obtained by PCR enrichment. At last, PCR products were purified (AMPure XP system) and library quality was assessed using the Agilent Bioanalyzer 2100 .

\section{Clustering, sequencing, and transcriptome assembly}

The clustering of the index-coded samples was performed on acBot Cluster Generation System using TruSeq PE Cluster Kitv3-cBot-HS (Illumina, San Diego, CA, USA). After cluster generation, the library preparations were sequenced on Illumina NovaSeq 6000 (Illumina, San Diego, CA, USA). After sequencing, the Q20, Q30, GC-content and sequence duplication level of the clean data (clean reads) were calculated.

Our lncRNA detection pipeline started with aligning the timecourse RNA-seq paired-end reads from each time point to the $M$. amblycephala genome [46] using Hisat2 [47]. The transcriptome was assembled using the StringTie [48] based on the reads aligned to the reference genome and was used to calculate FPKM (Fragments per kilobase of transcript per million mapped reads) of both lncRNAs and coding genes in each sample. The assembled transcripts were annotated using the GffCompare program [49]. The filter criteria of lncRNAs transcripts were included in the "i" (transcripts entirely within intron), " $x$ " (exonic overlap with reference on the opposite strand), "u" (intergenic transcripts), "o" (other same strand overlap with reference exons), and "e" (single exon transfrag partially covering an intron, possible
pre-mRNA fragment) classes [49]. According to the above standard, transcripts longer than 200 nucleotide (nt) and that have two or more exons [50] were screened, and the FPKM was set $\geq 0.1$. LncRNAs were screened using CPC2 [51]/ CNCI [52]/ Pfam [53]/ CPAT [54] that can distinguish the protein-coding genes from the non-coding genes.

\section{DEGs, DE IncRNAs analyses and functional annotation}

Differential expression analysis of the library was performed using DEseq2 [55]. LncRNAs or protein-coding genes with a false discovery rate $(\mathrm{FDR})<0.05$ and $\mid \log 2$ (Fold Change) $\mid \geq 1$ were assigned as differentially expressed. For each lncRNA locus, the $100 \mathrm{~kb}$ upstream and downstream protein-coding genes (without overlap) were identified as cis-acting target genes. The trans-acting target genes of IncRNA were predicted by a correlation analysis method between the expression of lncRNA and mRNA. To analyze the main function of the mRNAs and lncRNAs, the genes were annotated through GO [56] and KEGG pathway analyses [57]. GO terms analysis was performed using the OmicShare tools, an online platform (http://www.omicshare.com/tools) for data analysis. The KEGG pathways analysis was performed using BMKCloud (www.biocloud.net). GO terms and KEGG pathways with $P$-values $<0.05$ and the corrected $Q$-values $<0.05$ were considered significantly enriched.

\section{Co-expression network analysis}

Data were processed using the WGCNA package [58]. To ensure that the results of network construction are reliable, the abnormal values were removed. The soft threshold for network construction was selected to make sure that the network is closer to the real biological network state. The scale-free network was constructed using the blockwise modules function to group genes with similar patterns of expression.

The modules were defined by cutting the clustering tree into branches using a dynamic tree cutting algorithm and assigned to different colors for visualization [59]. To screen specific modules related to different time points post infection, the correlation coefficient $r$ and corresponding $P$-value between the feature vector of each module and different time points were calculated. Timespecific modules were identified based on the correlation between gene significance (GS) and module membership (MM). Modules with significantly correlated GS and MM $(P<0.01)$ were defined as time-specific. 
To further examine how lncRNAs cooperate with target genes to regulate fish immunity, co-expression analysis of the DE lncRNAs and the corresponding DE target genes was performed based on each time-specific module. Several differentially expressed immune-related mRNAs and predicted lncRNA-gene co-regulation pairs (COR $>0.8$ and $P<0.01$ ) were selected. Then Cytoscape 3.6 [60] was used to predict potential lncRNA targets with DEGs to build the lncRNA-gene co-expression network.

\section{Real-time fluorescent quantitative PCR (RT-qPCR) validation of IncRNA and gene expression}

To verify the results of high-throughput RNA-seq, RTqPCR was conducted. For the RT-qPCR analysis, $1 \mu \mathrm{g}$ of total RNA was reverse transcribed using the RT reagent Kits with gDNA Eraser (Takara, Dalian, China) according to the manufacturer's protocol. Six DE lncRNAs and four DEGs were chosen for RT-qPCR validation. Primer Premier 5.0 software was adopted to design the genespecific primers (Additional file 7: Table S7).

The reaction of RT-qPCR was performed with CFX Connect Real-Time PCR Detection System (BIO-RAD, USA) according to standard methods using LightCycler@480 SYBR Green I Master (Roche, USA). $18 \mathrm{~s}$ $r R N A$ was used as an internal control [44]. All experiments were performed in triplicate. The amount of target molecules relative to the control was calculated by using the $2^{-\Delta \Delta C t}$ method [61]. The results of RT-qPCR data were presented as mean \pm standard error of the mean (SEM) and were calculated by SPSS 22.0 (SPSS Inc., Chicago, IL, USA). Differences between the control and experimental treatments were analyzed by one-way analysis of variance (ANOVA) through Dunnett's multiple comparison. The level of statistical significance was set at $P<0.05$, and highly significance at $P<0.01$.

\section{Abbreviations}

LncRNAs: Long non-coding RNAs; bp: Base-pairs; GO: Gene Ontology; KEGG: Kyoto Encyclopedia of Genes and Genomes; WGCNA: Weighted correlation network analysis; RT-qPCR: Real-time fluorescent quantitative PCR: ceRNA: Competing endogenous RNA; miRNAs: MicroRNAs; MREs: MicroRNA response elements; AID: Autoimmune and immune-related disorders; IL$1 \beta$ : Interleukin-1 $\beta$; XOR: Xanthine oxidoreductase; iNOS: Inducible isoform of nitric oxide synthase; PPARs: Peroxisome proliferator-activated receptors; TLR: Toll-like receptors; hpi: Hour post infection; lincRNA: Intergenic IncRNA; FPKM: Fragments per kilobase of transcript per million mapped reads; nt: Nucleotide; DEGs: Differential expression genes; DE IncRNAs: Differentially expressed IncRNAs; FDR: False discovery rate; GS: Gene significance; MM: Module membership; SEM: Mean \pm standard error

\section{Supplementary Information}

The online version contains supplementary material available at https://doi. org/10.1186/s12864-021-07969-5.

Additional file 1: Supplementary Table 1. Statistical table of sample sequencing data evaluation.
Additional file 2: Supplementary Table 2 . Correlation of repeated samples.

Additional file 3: Supplementary Table 3.The target genes of IncRNAs.

Additional file 4: Supplementary Table 4. GO analysis of the differentially expressed genes.

Additional file 5: Supplementary Table 5. GO analysis of the target genes of differentially expressed IncRNAs.

Additional file 6: Supplementary Table 6. KEGG analysis of the target genes of differentially expressed IncRNAs.

Additional file 7: Table S7 Primers used for RT-qPCR.

Acknowledgments

We would like to thank Feng Zhang, Ming Ding, Hang Luo, Jian Zhang, Wanping Tian, Jiaqi Wu, Bo Li, Xiaohui Xu for the help in experiment and sampling.

\section{Authors' contributions}

QHS and HL designed the study. QHS, GWW and JXW contributed to the sample preparation and examination. GWW and JXW participated in the data analysis. QHS analyzed the biological information and wrote the article, and $\mathrm{HL}$ modified the language in the manuscript. HLW and HL gave technical advice and contributed to the study design. All authors read and approved the final manuscript.

\section{Authors' information}

Not applicable.

\section{Funding}

This project was supported by grants from National Natural Science Foundation of China (31972781) and the Earmarked Fund for China Agriculture Research System titled as-Staple Freshwater Fishes Industry Technology System (Grant No. CARS-46-08).

\section{Availability of data and materials}

The sequencing data in this study were deposited in the Seq Read Archive (SRA) database (accession number: PRJNA716731) at https://www.ncbi.nlm. nih.gov/bioproject/PRJNA716731.

\section{Declarations}

\section{Ethics approval and consent to participate}

We have adhered to all local, national and international regulations and conventions, and we respected normal scientific ethical practices. The specimen used in this study comes from a population that was part of commercially fished individuals intended for human consumption. The animal protocol was approved by the Institutional Animal Care and Use Ethics Committee of Huazhong Agricultural University (Wuhan, China) (HZAUFI-2019-026). The study complies with the ARRIVE guidelines (Animal Research: Reporting in Vivo Experiments).

Consent for publication

Not applicable.

\section{Competing interests}

The authors declare that they have no conflict of interest.

Received: 24 March 2021 Accepted: 28 August 2021

Published online: 11 September 2021

\section{References}

1. Rinn JL, Chang HY. Genome regulation by long noncoding RNAs. Annu Rev Biochem. 2012;81(1):145-66. https://doi.org/10.1146/annurev-biochem051410-092902.

2. Ponting $C P$, Oliver PL, Reik W. Evolution and functions of long noncoding RNAs. Cell. 2009;136(4):629-41. https://doi.org/10.1016/j.cell.2009.02.006.

3. Atianand MK, Caffrey DR, Fitzgerald KA. Immunobiology of long noncoding RNAs. Annu Rev Immunol. 2017:35(1):177-98. https://doi.org/10.1146/a nnurev-immunol-041015-055459. 
4. Wilusz JE, Sunwoo H, Spector DL. Long noncoding RNAs: functional surprises from the RNA world. Genes Dev. 2009;23(13):1494-504. https://doi. org/10.1101/gad.1800909.

5. Kim J, Piao HL, Kim BJ, Yao F, Han Z, Wang Y, et al. Long noncoding RNA MALAT1 suppresses breast cancer metastasis. Nat Genet. 2018;50(12):170515. https://doi.org/10.1038/s41588-018-0252-3.

6. Batista PJ, Chang HY. Long noncoding RNAs: cellular address codes in development and disease. Cell. 2013;152(6):1298-307. https://doi.org/10.101 6/j.cell.2013.02.012.

7. Zhu J, Fu H, Wu Y, Zheng X. Function of IncRNAs and approaches to IncRNA-protein interactions. Sci China Life Sci. 2013;56(10):876-85. https:// doi.org/10.1007/s11427-013-4553-6.

8. Carpenter S. Editorial: functions of non-coding RNA in innate immunity. Front Immunol. 2015;6:622. https://doi.org/10.3389/fimmu.2015.00622.

9. Ouyang J, Hu J, Chen JL. IncRNAs regulate the innate immune response to viral infection. Wiley Interdiscip Rev RNA. 2016;7(1):129-43. https://doi.org/1 0.1002/wrna.1321.

10. Bartel DP. MicroRNAs: genomics, biogenesis, mechanism, and function. Cell. 2004;116(2):281-97. https://doi.org/10.1016/S0092-8674(04)00045-5.

11. Zur Bruegge J, Einspanier R, Sharbati S. A long journey ahead: long noncoding RNAs in bacterial infections. Front Cell Infect Mi. 2017;7:95. https:// doi.org/10.3389/fcimb.2017.00095.

12. Salmena L, Poliseno L, Tay $Y$, Kats L, Pandolfi PP. A ceRNA hypothesis: the Rosetta stone of a hidden RNA language? Cell. 2011;146(3):353-8. https:// doi.org/10.1016/j.cell.2011.07.014.

13. Sen R, Ghosal S, Das S, Balti S, Chakrabarti J. Competing endogenous RNA: the key to posttranscriptional regulation. ScientificWorldJournal. 2014; 2014(6):896206. https://doi.org/10.1155/2014/896206.

14. Kartha RV, Subramanian S. Competing endogenous RNAs (ceRNAs): new entrants to the intricacies of gene regulation. Front Genet. 2014;5:8. https:// doi.org/10.3389/fgene.2014.00008.

15. Ebert MS, Neilson JR, Sharp PA. MicroRNA sponges: competitive inhibitors of small RNAs in mammalian cells. Nat Methods. 2007;4(9):721-6. https://doi. org/10.1038/nmeth1079.

16. Cech TR, Steitz JA. The noncoding RNA revolution-trashing old rules to forge new ones. Cell. 2014;157(1):77-94. https://doi.org/10.1016/j.cell.2014.03.008.

17. Hrdlickova B, Kumar V, Kanduri K, Zhernakova DV, Tripathi S, Karjalainen J, et al. Expression profiles of long non-coding RNAs located in autoimmune disease-associated regions reveal immune cell-type specificity. Genome Med. 2014;6(10):88. https://doi.org/10.1186/s13073-014-0088-0.

18. Peng X, Gralinski L, Armour CD, Ferris MT, Thomas MJ, Proll S, et al. Unique signatures of long noncoding RNA expression in response to virus infection and altered innate immune signaling. mBio. 2010;1(5).

19. Li R, Fang L, Pu Q, Bu H, Zhu P, Chen Z, et al. MEG3-4 is a miRNA decoy that regulates $\mathrm{IL}-1$ beta abundance to initiate and then limit inflammation to prevent sepsis during lung infection. Sci Signal. 2018;11(536):eaao2387.

20. Heward JA, Lindsay MA. Long non-coding RNAs in the regulation of the immune response. Trends Immunol. 2014;35(9):408-19. https://doi.org/10.1 016/j.it.2014.07.005

21. Wang $X$, Lin J, Li F, Zhang C, Li J, Wang C, et al. Screening and functional identification of IncRNAs under beta-diketone antibiotic exposure to zebrafish (Danio rerio) using high-throughput sequencing. Aquat Toxicol. 2017;182:214-25. https://doi.org/10.1016/j.aquatox.2016.12.003.

22. Wei N, Pang W, Wang Y, Xiong Y, Xu R, Wu W, et al. Knockdown of PU.1 mRNA and AS IncRNA regulates expression of immune-related genes in zebrafish Danio rerio. Dev Comp Immunol. 2014;44(2):315-9. https://doi. org/10.1016/j.dci.2014.01.015.

23. Paneru B, Al-Tobasei R, Palti Y, Wiens GD, Salem M. Differential expression of long non-coding RNAs in three genetic lines of rainbow trout in response to infection with Flavobacterium psychrophilum. Sci Rep. 2016;6(1):36032. https://doi.org/10.1038/srep36032.

24. Valenzuela-Miranda D, Gallardo-Escarate C. Novel insights into the response of Atlantic salmon (Salmo salar) to Piscirickettsia salmonis: interplay of coding genes and IncRNAs during bacterial infection. Fish Shellfish Immunol. 2016;59:427-38. https://doi.org/10.1016/j.fsi.2016.11.001.

25. Moller AM, Korytar T, Kollner B, Schmidt-Posthaus $H$, Segner $H$. The teleostean liver as an immunological organ: intrahepatic immune cells (IHICS) in healthy and benzo[a]pyrene challenged rainbow trout (Oncorhynchus mykiss). Dev Comp Immunol. 2014;46(2):518-29. https://doi. org/10.1016/j.dci.2014.03.020.
26. Castro R, Abos B, Pignatelli J, von Gersdorff JL, Gonzalez Granja A, Buchmann $\mathrm{K}$, et al. Early immune responses in rainbow trout liver upon viral hemorrhagic septicemia virus (VHSV) infection. PLoS One. 2014;9(10): e111084. https://doi.org/10.1371/journal.pone.0111084.

27. Yang Y, Han T, Xiao J, Li X, Wang J. Transcriptome analysis reveals carbohydrate-mediated liver immune responses in Epinephelus akaara. Sci Rep. 2018;8(1):639. https://doi.org/10.1038/s41598-017-18990-8.

28. Bayne $C J$, Gerwick $L$. The acute phase response and innate immunity of fish. Dev Comp Immunol. 2001;25(8-9):725-43. https://doi.org/10.1016/S0145-3 05X(01)00033-7.

29. Boltaña S, Valenzuela-Miranda D, Aguilar A, Mackenzie S, Gallardo-Escárate C. Long noncoding RNAs (IncRNAs) dynamics evidence immunomodulation during ISAV-Infected Atlantic salmon (Salmo salar). Sci Rep. 2016;6(1). https://doi.org/10.1038/srep22698.

30. Tarifeno-Saldivia E, Valenzuela-Miranda D, Gallardo-Escarate C. In the shadow: the emerging role of long non-coding RNAs in the immune response of Atlantic salmon. Dev Comp Immunol. 2017;73:193-205. https:// doi.org/10.1016/j.dci.2017.03.024.

31. Liu X, Li W, Jiang L, Lu Z, Liu M, Gong L, et al. Immunity-associated long non-coding RNA and expression in response to bacterial infection in large yellow croaker (Larimichthys crocea). Fish Shellfish Immunol. 2019;94:634-42. https://doi.org/10.1016/j.fsi.2019.09.015.

32. Tuan TN. Transcriptome analysis and expression of immune-related genes in Megalobrama amblycephala after challenge with Aeromonas hydrophila. PhD dissertation. Wuhan: Huazhong Agricutural University Library; 2015.

33. Louro R, El-Jundi T, Nakaya HI, Reis EM, Verjovski-Almeida S. Conserved tissue expression signatures of intronic noncoding RNAs transcribed from human and mouse loci. Genomics. 2008;92(1):18-25. https://doi.org/10.101 6/j.ygeno.2008.03.013.

34. Gostner JM, Becker K, Fuchs D, Sucher R. Redox regulation of the immune response. Redox Rep. 2013;18(3):88-94. https://doi.org/10.1179/1351000213 Y.0000000044.

35. Madigan MC, McEnaney RM, Shukla AJ, Hong G, Kelley EE, Tarpey MM, et al. Xanthine oxidoreductase function contributes to Normal wound healing. Mol Med. 2015;21(1):313-22. https://doi.org/10.2119/molmed.2014.00191.

36. Rodriguez I, Novoa B, Figueras A. Immune response of zebrafish (Danio rerio) against a newly isolated bacterial pathogen Aeromonas hydrophila. Fish Shellfish Immunol. 2008;25(3):239-49. https://doi.org/10.1016/j.fsi.2008. 05.002 .

37. Pautz A, Art J, Hahn S, Nowag S, Voss C, Kleinert H. Regulation of the expression of inducible nitric oxide synthase. Nitric Oxide. 2010;23(2):75-93. https://doi.org/10.1016/j.niox.2010.04.007.

38. Wang C, Li P, Liu L, Pan H, Li H, Cai L, et al. Self-adjuvanted nanovaccine for cancer immunotherapy: role of lysosomal rupture-induced ROS in MHC class I antigen presentation. Biomaterials. 2016;79:88-100. https://doi.org/1 0.1016/j.biomaterials.2015.11.040.

39. Ngoka LC. Dramatic down-regulation of oxidoreductases in human hepatocellular carcinoma hepG2 cells: proteomics and gene ontology unveiling new frontiers in cancer enzymology. Proteome Sci. 2008;6(1):29. https://doi.org/10.1186/1477-5956-6-29.

40. Jorgensen SM, Afanasyev S, Krasnov A. Gene expression analyses in Atlantic salmon challenged with infectious salmon anemia virus reveal differences between individuals with early, intermediate and late mortality. BMC Genomics. 2008;9(1):179. https://doi.org/10.1186/1471-2164-9-179.

41. Fanale D, Amodeo V, Caruso S. The interplay between metabolism, PPAR signaling pathway, and Cancer. PPAR Res. 2017;2017:1830626-2. https://doi. org/10.1155/2017/1830626.

42. Ganz T. Hepcidin, a key regulator of iron metabolism and mediator of anemia of inflammation. Blood. 2003;102(3):783-8. https://doi.org/10.1182/ blood-2003-03-0672.

43. Ding Z, Zhao X, Zhan Q, Cui L, Sun Q, Wang W, et al. Comparative analysis of two ferritin subunits from blunt snout bream (Megalobrama amblycephala): characterization, expression, iron depriving and bacteriostatic activity. Fish Shellfish Immunol. 2017;66:411-22. https://doi.org/10.1016/j.fsi.2 017.05.032.

44. Ding Z, Zhao X, Su L, Zhou F, Chen N, Wu J, et al. The Megalobrama amblycephala transferrin and transferrin receptor genes: molecular cloning, characterization and expression during early development and after Aeromonas hydrophila infection. Dev Comp Immunol. 2015;49(2):290-7. https://doi.org/10.1016/j.dci.2014.12.010 
45. Nemeth E, Ganz T. Regulation of iron metabolism by hepcidin. Annu Rev Nutr. 2006;26(1):323-42. https://doi.org/10.1146/annurev.nutr.26.061505.1113 03.

46. Liu H, Chen C, Gao Z, Min J, Gu Y, Jian J, et al. The draft genome of blunt snout bream (Megalobrama amblycephala) reveals the development of intermuscular bone and adaptation to herbivorous diet. Gigascience. 2017; 6(7):1-13. https://doi.org/10.1093/gigascience/gix039.

47. Li J, Ma W, Zeng P, Wang J, Geng B, Yang J, et al. LncTar: a tool for predicting the RNA targets of long noncoding RNAs. Brief Bioinform. 2015; 16(5):806-12. https://doi.org/10.1093/bib/bbu048.

48. Kim D, Langmead B, Salzberg SL. HISAT: a fast spliced aligner with low memory requirements. Nat Methods. 2015;12(4):357-60. https://doi.org/10.1 038/nmeth.3317.

49. Pertea G, Pertea M. GFF Utilities: GffRead and GffCompare. F1000Res. 2020;9: 304

50. Kelley D, Rinn J. Transposable elements reveal a stem cell-specific class of long noncoding RNAs. Genome Biol. 2012;13(11):R107. https://doi.org/10.11 86/gb-2012-13-11-r107

51. Kong L, Zhang Y, Ye ZQ, Liu XQ, Zhao SQ, Wei L, et al. CPC: assess the protein-coding potential of transcripts using sequence features and support vector machine. Nucleic Acids Res. 2007;35(Web Server issue):W345-9.

52. Sun L, Luo H, Bu D, Zhao G, Yu K, Zhang C, et al. Utilizing sequence intrinsic composition to classify protein-coding and long non-coding transcripts. Nucleic Acids Res. 2013;41(17):e166. https://doi.org/10.1093/nar/gkt646.

53. Finn RD, Tate J, Mistry J, Coggill PC, Sammut SJ, Hotz HR, et al. The Pfam protein families database. Nucleic Acids Res. 2008;36(Database issue):D2818. https://doi.org/10.1093/nar/gkm960.

54. Wang L, Park HJ, Dasari S, Wang S, Kocher JP, Li W. CPAT: coding-potential assessment tool using an alignment-free logistic regression model. Nucleic Acids Res. 2013;41(6):e74. https://doi.org/10.1093/nar/gkt006.

55. Love Ml, Huber W, Anders S. Moderated estimation of fold change and dispersion for RNA-seq data with DESeq2. Genome Biol. 2014;15(12):550. https://doi.org/10.1186/s13059-014-0550-8

56. Ashburner M, Ball CA, Blake JA, Botstein D, Butler H, Cherry JM, et al. Gene ontology: tool for the unification of biology. The Gene Ontology Consortium. Nat Genet. 2000;25(1):25-9. https://doi.org/10.1038/75556.

57. Kanehisa M, Goto S, Kawashima S, Okuno Y, Hattori M. The KEGG resource for deciphering the genome. Nucleic Acids Res. 2004;32(Database issue): D277-80. https://doi.org/10.1093/nar/gkh063.

58. Langfelder P, Horvath S. WGCNA: an R package for weighted correlation network analysis. BMC Bioinformatics. 2008;9(1):559. https://doi.org/10.11 86/1471-2105-9-559.

59. Yang Q, Wang R, Wei B, Peng C, Wang L, Hu G, et al. Candidate biomarkers and molecular mechanism investigation for glioblastoma multiforme utilizing WGCNA. Biomed Res Int. 2018;2018:4246703.

60. Shannon P, Markiel A, Ozier O, Baliga NS, Wang JT, Ramage D, et al. Cytoscape: a software environment for integrated models of biomolecular interaction networks. Genome Res. 2003;13(11):2498-504. https://doi.org/1 $0.1101 /$ gr.1239303

61. Livak KJ, Schmittgen TD. Analysis of relative gene expression data using real-time quantitative PCR and the 2(-Delta Delta C(T)) method. Methods. 2001;25(4):402-8. https://doi.org/10.1006/meth.2001.1262.

\section{Publisher's Note}

Springer Nature remains neutral with regard to jurisdictional claims in published maps and institutional affiliations.

Ready to submit your research? Choose BMC and benefit from:

- fast, convenient online submission

- thorough peer review by experienced researchers in your field

- rapid publication on acceptance

- support for research data, including large and complex data types

- gold Open Access which fosters wider collaboration and increased citations

- maximum visibility for your research: over $100 \mathrm{M}$ website views per year

At BMC, research is always in progress.

Learn more biomedcentral.com/submissions 